\title{
PENGEMBANGAN PERTANIAN BUDIDAYA LORONG (ALLEY CROPPING) UNTUK KONSERVASI LAHAN KRITIS DI HULU DAERAH ALIRAN SUNGAI (DAS) CIMANUK, JAWA BARAT
}

\author{
Daru Mulyono \\ Peneliti di Pusat Teknologi Produksi Pertanian \\ Badan Pengkajian dan Penerapan Teknologi
}

\begin{abstract}
The role and function of Cimanuk Watershed tend to declining, where total of critical area reach to a high of 131,384 ha from the total of 358,400 ha or about $36.6 \%$. In wet season debit of Cimanuk River reach 1,004 $\mathrm{m}^{3} / \mathrm{second}$ and in dry season reavh $4 \mathrm{~m}^{3} / \mathrm{second}$. Therefore the Debit Ratio of Cimanuk River reach to a high of 251, it is indicate that Cimanuk Watershed become very critical condition and need appropriate management especially in the upper watershed. One altervative of the watershed management is application of Alley Cropping system. The biomass from prunning of hedgerows Flemengia congesta have significant effect to land fertility through improvement of nutrients availability. Furthermore, the successful application of Alley Cropping system will lead to conserve land and water where it will support flood control, agricultural irrigation, fisheries development, electric generation, industrial development, etc.
\end{abstract}

Keywords: agricultural, alley cropping, land conservation, watershed

\section{PENDAHULUAN}

Hampir seluruh Daerah Aliran Sungai (DAS) besar yang ada di Jawa Barat telah mengalami kerusakan berat. Dari jumlah 40 DAS yang ada di Jawa Barat, 18 DAS mengarah ke arah utara dan 22 DAS mengarah ke arah selatan semuanya telah masuk dalam kondisi yang kritis ${ }^{21)}$. Kerusakan DAS terutama terjadi pada hulu sungai di daerah penyangga atau kawasan hutan lindung. Kerusakan DAS inilah yang antara lain memicu terjadinya banjir. Menurut Staf Ahli Menteri Negara Lingkungan Hidup pada tahun 2002 di Indonesia terdapat 62 titik banjir dimana jumlah ini pada tahun 2006 meningkat menjadi 72 titik banjir, dimana sebagian besar titik banjir ini terdapat di
Jawa Barat ${ }^{4)}$. Diantara DAS yang rusak salah satunya adalah DAS Cimanuk yang telah mengalami rusak sangat parah ${ }^{12)}$.

Wilayah DAS Cimanuk merupakan bagian dari DAS Cimanuk-Cisanggarung. Areal DAS Cimanuk mencakup empat Kabupaten di Jawa Barat, yaitu: Kabupaten Garut, Sumedang, Majalengka, dan Indramayu. Secara administratif Wilayah DAS Cimanuk-Cisanggarung terletak di Propinsi Jawa Barat dan Jawa Tengah, secara astronomis terletak pada 107 010" BT-109 000" BT dan 6 000" LS-7 030"LS dengan luas daerah tangkapan (catchment area) meliputi $7.711 \mathrm{~km}^{2}{ }^{1)}$. Sedangkan DAS Cimanuk sendiri meliputi areal seluas $3.584 \mathrm{~km}^{2}{ }^{17}$ ) 
dengan topografi yang sangat beragam, dimana pada bagian hulu cenderung berbukit dan permukaan membentuk lereng, pada bagian tengah didominasi oleh daerah sedikit bergelombang, sedangkan pada bagian hilir merupakan daerah datar.

Permasalah besar yang dialami DAS Cimanuk pada saat ini adalah gundulnya hutan di wilayah hulu. Gundulnya hutan di wilayah hulu Sungai Cimanuk mengakibatkan banjir pada musim hujan dan kekeringan pada musim kemarau. Pada saat musim hujan debit air sungai Cimanuk sangat besar, yakni sebesar $1.004 \mathrm{~m}^{3}$ per detik dan pada saat musim kemarau hanya $4 \mathrm{~m}^{3}$ per detik, berarti rasio debit di sungai Cimanuk mencapai $251{ }^{12)}$. Tingginya rasio ini menunjukkan tingkat kerusakan DAS yang sudah sangat parah. Menurut data Departemen Pekerjaan Umum, tahun 2010 ini luas lahan kritis di DAS Cimanuk telah mencapai 131.384 ha atau sekitar 36,6 \% dari total luas DAS ${ }^{12}$. Lebih lanjut Sungai Cimanuk ini terkenal dengan arus air yang sangat deras pada musim hujan sehingga membawa lapisan tanah bagian atas (top soil) yang subur yang mengakibatkan lahan cepat menjadi kritis.

Dengan demikian diperlukan penanganan yang tepat dan memadai agar peran dan fungsi DAS Cimanuk dapat dikembalikan secara optimal. Hal ini telah dilakukan oleh Pemerintah Provinsi Jawa Barat bekerjasma dengan Kementerian Pertanian dan Kementerian Pekerjaan Umum melakukan Gerakan Konservasi DAS Cimanuk. Gerakan Konservasi DAS Cimanuk dilakukan dengan melibatkan langsung partisipasi masyarakat melalui program penghijauan di daerah gundul khususnya di hulu DAS Cimanuk. Konservasi DAS Cimanuk saat ini mendapatkan prioritas penanganan karena direncanakan air Sungai Cimanuk merupakan pemasok utama air Waduk Jati Gede, Sumedang yang sekarang sedang dalam tahap pembangunan. Waduk Jati Gede ini memiliki luas daerah tangkapan (catchment area) sebesar 1.462 $\mathrm{km}^{2}{ }^{1)}$ yang akan mampu menampung air sebesar kurang lebih satu milyar $\mathrm{m}^{3}$ air yang rencananya akan digunakan sebagai waduk serbaguna untuk berbagai kepentingan, seperti: pengendali banjir, sumber air irigasi, pengembangan perikanan, pengembangan pariwisata, maupun pembangkit listrik tenaga air (PLTA).

Untuk itu guna menunjang berhasilnya Gerakan Konservasi DAS Cimanuk diusulkan untuk dikembangkan sistem Budidaya Lorong. Sistem Budidaya Lorong biasanya dilakukan di lahan kering dengan kemiringan antara 10 sampai dengan $20 \%$, dimana tanaman pangan ditanam diantara tanaman pagar yang berupa pohon, seperti Flemengia congesta. Secara periodik tanaman pagar ini dipangkas agar tanaman utama tidak ternaungi dan pada saat bersamaan menambahkan biomas ke dalam tanah. Dengan cara pengolahan tanah yang baik, pemberian kapur serta penambahan biomas dari tanaman pagar diharapkan tanah akan menjadi semakin produktif/subur. Meningkatnya produktivitas tanah ditandai dengan: lebih tersedianya unsur hara tanah, peningkatan kapasitas tukar kation (KTK), memperbaiki struktur tanah, dan memperbaiki sifat biologi tanah ${ }^{19}$. Dampak pengembangan agroforestri ini diharapkan akan meningkatkan peran dan fungsi DAS Cimanuk sehingga secara optimal dapat dimanfaatkan oleh masyarakat untuk meningkatkan kesejahteraannya secara berkesinambungan.

\section{KONDISI HULU DAS CIMANUK}

Pada saat ini kondisi DAS di Indonesia terus mengalami kerusakan bahkan tidak sedikit yang sudah tergolong rusak berat. Menurut data dari Departemen Kehutanan pada tahun 1999 di Indonesia terdapat 458 DAS yang kritis atau rusak berat, dimana 26 diantaranya terdapat di Pulau Jawa ${ }^{13)}$. Terjadinya penggundulan hutan yang terus menerus dan tidak terkendali terutama di daerah hulu DAS membuat kemampuan DAS untuk menyimpan air semakin berkurang. Bahkan kawasan hutan konservasi pun 
telah banyak yang dibabat untuk berbagai kepentingan. Dari hasil analisis yang menggunakan citra landsat pada tahun 2005 menunjukkan bahwa luas hutan di Pulau Jawa tinggal kurang lebih 40.000 ha. Dengan demikian lahan yang tertutup oleh vegetasi diperkirakan hanya mencapai kurang lebih $21 \%{ }^{13)}$. Padahal menurut amanat Undangundang Nomor 26 tahun 2007 mengenai Penataan Ruang, secara jelas disebutkan bahwa luas minimal berupa hutan atau lahan terbuka hijau setidaknya $30 \%$.

Di wilayah hulu DAS Cimanuk pun telah terjadi penggundulan hutan yang sudah termasuk dalam kategori parah yang mengakibatkan lahan menjadi kritis. Tercatat lahan kritis di DAS Cimanuk saat ini telah mencapai 131.384 ha atau sekitar $36,6 \%$ dari total luas DAS ${ }^{12}$. Lebih lanjut, sebagai akibat semakin rusaknya DAS ini adalah semakin besarnya tingkat erosi tanah yang mengancam rusaknya saluran irigasi maupun cepatnya pendangkalan waduk. Di Indonesia pada tahun 2008 tercatat luas lahan yang terairi oleh air irigasi mencapai luas 3,28 juta ha dimana ada sekitar 379,76 ha terpaksa tidak dapat dialiri air karena tidak berfungsinya jaringan irigasi sebagai akibat pendangkalan ${ }^{13)}$. Berikut ini adalah tingkat erosi dari beberapa sungai di Pulau Jawa yang disajikan pada Tabel 1.

Tabel 1. Tingkat Erosi Beberapa Sungai

\begin{tabular}{|c|c|c|}
\hline No. & $\begin{array}{c}\text { Sungai \& } \\
\text { Lokasi }\end{array}$ & $\begin{array}{c}\text { Erosi } \\
\text { (mm/th) }\end{array}$ \\
\hline 1. & S. Cilutung, Majalengka & 78 \\
\hline 2. & S. Cimanuk, Indramayu & 120 \\
\hline 3. & S. Cacaban, Brebes & 38 \\
\hline 4. & S. Citanduy, Banjar & 37 \\
\hline 5. & S. Bengawan Solo & 23 \\
\hline 6. & S. Kalimadiun, Madiun & 21 \\
\hline
\end{tabular}

Sumber: ${ }^{7}$.

Dari data tingkat erosi tersebut menunjukkan bahwa Sungai Cimanuk memiliki tingkat erosi yang sangat besar, yaitu $120 \mathrm{~mm} /$ tahun. Menurut Sitanala Arsyad tingkat erosi terbesar yang masih ditoleransi adalah sebesar 2,5 mm/tahun 7). Oleh karena itu dalam pembangunan Waduk Jati Gede, Sumedang yang saat ini sedang dilakukan, akan beresiko tinggi bila tidak dilakukan upaya penanganan yang memadai khususnya dalam mengelola DAS Cimanuk. Pengelolaan ini terutama adalah mendorong masyarakat untuk lebih peduli dan berpartisipasi langsung dalam upaya pengendalian dan rehabilitasi lahan kritis di wilayah hulu DAS Cimanuk.

Pada saat musim hujan debit air sungai Cimanuk sangat besar, yakni sebesar $1.004 \mathrm{~m}^{3}$ per detik dan pada saat musim kemarau hanya $4 \mathrm{~m}^{3}$ per detik ${ }^{12}$ ). Nilai rasio debit maksimum pada musim hujan dan debit minimum pada musim kemarau atau $Q_{\max } / Q_{\min }$ menjukkan efektifitas suatu DAS dalam menyimpan surplus air pada musim hujan yang kemudian dapat dialirkan pada musim kemarau ${ }^{13)}$. Berikut ini beberapa nilai rasio beberapa sungai di Pulau Jawa yang disajikan pada Tabel 2.

Tabel 2. Nilai Rasio Debit Sungai di Pulau Jawa

\begin{tabular}{|l|l|l|}
\hline No. & \multicolumn{1}{|c|}{ Sungai } & $\begin{array}{c}\text { Rasio } \mathbf{Q}_{\max } \text { I } \\
\mathbf{Q}_{\min }\end{array}$ \\
\hline 1. & Cimanuk (Jawa Barat) & 251 \\
\hline 2. & Ciujung (Banten) & $22-179$ \\
\hline 3. & Bengawan Solo (Jateng) & 106 \\
\hline 4. & Brantas (Jatim) & $8-12$ \\
\hline 5. & Progo (DIY) & $400-588$ \\
\hline
\end{tabular}

Sumber: 12, 13)

Dari data tersebut terlihat bahwa Sungai Cimanuk memiliki rasio debit maksimum pada musim hujan dan debit minimum pada musim kemarau adalah 251, dimana nilai ini tergolong tinggi dibandingkan dengan beberapa sungai lain di Pulau Jawa. Semakin besar nilai rasio ini memberikan gambaran bahwa kondisi DAS yang semakin buruk atau kritis. Besarnya rasio tersebut menunjukkan tingkat erosi yang tinggi dimana akan membawa lapisan tanah atas (top soil) 
yang subur sehingga mengakibatkan lahan terutama di hulu DAS Cimanuk menjadi semakin kritis.

Menurut hasil pengamatan pihak Kesatuan Pemangkuan Hutan (KPH) Garut pada tahun 2009, menunjukkan bahwa kondisi area hutan di DAS Cimanuk sangat memprihatinkan. Berikut ini gambar kondisi kritis di wilayah hulu DAS Cimanuk yang disajikan pada Gambar 1.

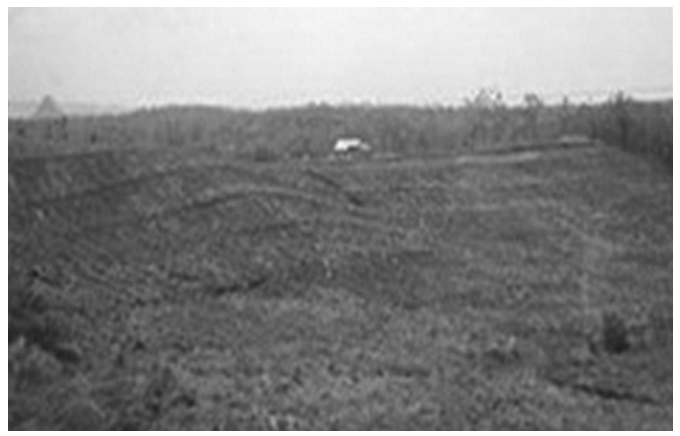

Gambar 1. Kondisi Hulu DAS Cimanuk yang Kritis

Dari total luas hutan sebesar 17.000 ha, paling sedikit ada lahan hutan seluas $3.993,45$ ha yang rusak akibat tindakan perambahan hutan secara liar yang dilakukan oleh masyarakat setempat. Sejumlah lokasi yang rusak tersebut meliputi 376,41 ha berada di kawasan Limbangan, Kadungora, dan Tarogong, 2.126,62 ha berada di kawasan Cisurupan dan Simpang Bayongbong serta $1.490,42$ ha berada di kawasan Mandalagiri, Cikajang ${ }^{9}$.

Menurut data dari Balai Besar Wilayah Sungai Cimanuk-Cisanggarung terdapat tiga lokasi yang mengalami kerusakan lahan hingga parah atau menjadi sangat kritis, yaitu di: (1). Cimanuk Hulu, dengan luas 8.057 ha, berada di Kabupaten Garut, (2). Cikamiri-Ciroyom, dengan luas 3.572 ha, berada di Kabupaten Garut, dan (3). CialingCicacaban, dengan luas 6.618 ha, berada di Kabupaten Sumedang ${ }^{2)}$. Bila keadaan ini terus dibiarkan maka akan mengakibatkan menurunnya produksi pertanian, terjadi banjir yang semakin besar, rusaknya jaringan irigasi, cepatnya pendangkalan waduk Jati Gede, Sumedang (yang saat ini sedang dalam pembangunan). Apabila waduk telah dibangun dan daerah tangkapan air di hulu tidak diperbaiki, maka Waduk Jati Gede akan segera penuh lumpur sehingga tidak sesuai dengan umur operasional yang ditetapkan. Oleh karena itu diperlukan penanganan lahan kritis yang tepat di wilayah hulu DAS Cimanuk agar dampak agar dampak negatif yang ditimbulkan dapat ditekan seminimal mungkin, antara lain adalah melalui pengembangan budidaya lorong.

\section{PENGEMBANGAN BUDIDAYA LORONG}

Budidaya lorong (alley cropping) pada dasarnya adalah menanam tanaman pagar yang ditanam rapat mengikuti garis kontur dan tanaman pokok yang berupa tanaman semusim (pangan atau hortikultura yang bernilai ekonomi tinggi) yang ditanam pada loronglorong diantara tanaman pagar. Tanaman pagar ini dipangkas secara berkala terutama bila tanaman pagar mulai menaungi tanaman pokok, dimana biomass tanaman pagar ini ditumpuk merata di lorong-lorong antara tanaman pagar. Oleh karena itu jenis tanaman pagar ini dipilih dari jenis yang memiliki sifatsifat: (a). Cepat tumbuh dan bertunas kembali sehingga menghasilkan banyak hijauan, (b). Tingkat persaingan terhadap unsur hara dan air dengan tanaman pokok relatif rendah. (c). Memiliki perakaran vertikal yang dalam sehingga mampu menahan erosi tanah. Tanaman pagar yang mempunyai penyebaran akar lateral (menyebar pada lapisan dan (d). Tidak bersifat alelopatik (mengeluarkan zat racun) terhadap tanaman pokok ${ }^{3)}$.

Dengan demikian teknik budidaya lorong ini dilakukan atas dasar prinsipprinsip konservasi tanah, dengan unsur pokok adalah tanaman pagar yang berperan sebagai pengontrol erosi yang efektif 11). Beberapa jenis tanaman pagar yang biasanya digunakan dalam budidaya lorong adalah sebagai berikut: 
Tabel 3. Beberapa Jenis Tanaman Pagar

\begin{tabular}{|l|l|l|}
\hline No. & \multicolumn{1}{|c|}{ Jenis Tanaman } & Pertumbuhan \\
\hline 1. & Caliandra callothyrsus & Cepat \\
\hline 2. & Gliricidia sepium & Cepat \\
\hline 3. & Leucaena leucocephala & Cepat \\
\hline 4. & Leucaena diversifolia & Cepat \\
\hline 5. & Tephrosia volgelli & Cepat \\
\hline 6. & Vetiveria zizanioides & Cepat \\
\hline 7. & Capanus cajosi & Sedang \\
\hline 8. & Flemingia congesta & Lambat \\
\hline
\end{tabular}

Sumber: ${ }^{11)}$

Tanaman pagar dalam budidaya lorong ini biasanya ditanam dalam barisan tanaman perdu yang ditanam secara rapat dengan jarak tanam biasanya antara $10-25 \mathrm{~cm}$ tergantung pada jenis tanaman pagarnya. Dibandingkan dengan pembuatan teras bangku untuk konservasi lahan, biaya budidaya lorong ini jauh lebih murah dan cukup efektif dalam menahan erosi bahkan mendukung lahan yang semakin subur. Dalam waktu yang relatif tidak lama sekitar tiga sampai empat tahun sejak tanaman pagar ditanam biasanya telah terbentuk teras secara alami sehingga teras jenis ini sering disebut sebagai teras kredit yang berguna dalam menahan erosi tanah ${ }^{3)}$. Oleh karena itu budidaya lorong ini memiliki arti yang sangat penting dalam upaya konservasi lahan terutama di lahan wilayah hulu DAS yang berlereng dan kebanyakan kondisinya telah gundul/kritis. Berikut ini adalah gambar pertanian budidaya lorong (Gambar 2).

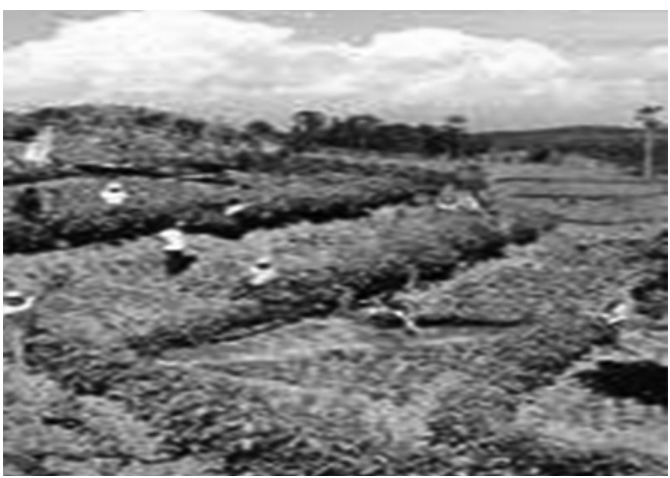

Gambar 2. Pertanian Budidaya Lorong
Dalam pertanian sistem budidaya lorong akan terjadi interaksi yang saling menguntungkan antara tanaman pagar dengan tanaman pokok, antara lain adalah: (a). Serasah dari tanaman pagar berperan menurunkan kehilangan air melalui evaporasi dari permukaan tanah sehingga akan memperbaiki kelembaban tanah, (b). Naungan tanaman pagar dapat menekan pertumbuhan gulma (misalnya Imperata cylindrica) sehingga akan mengurangi resiko kebakaran pada musim kemarau, dan (c). Tanaman pagar (khususnya dari jenis leguminosa) dapat mengikat unsur nitrogen $\left(\mathrm{N}_{2}\right)$ secara biologis dari udara sehingga akan menurunkan kebutuhan pupuk nitrogen 10).

Pertanian budidaya lorong ini sangat cocok dilakukan di daerah yang berlereng seperti di wilayah hulu DAS Cimanuk yang memiliki tingkat kelerengan antara 10-30 $\%$. Setelah terjadi penebangan hutan di wilayah hulu DAS Cimanuk yang memiliki kemiringan tanah dan curah hujan yang tinggi mengakibatkan tanah menjadi gundul dan kesuburan tanah menurun karena adanya erosi yang membawa lapisan tanah bagian atas (top soil) yang subur. Tanah yang telah gundul ini pada umumnya kurang subur dengan ciri-ciri sebagai berikut: rendahnya $\mathrm{pH}$, miskin unsur hara (khususnya N, P, K, Ca, dan Mg), rendahnya kapasitas tukar kation (KTK), rendahnya kadar biomas, dan tingginya konsentrasi aluminium ( $\mathrm{Al}$ ) pada tingkat yang meracuni 6). Untuk itu penerapan budidaya lorong yang menghasilkan pangkasan atau biomas dari tanaman pagar akan berperan meningkatkan kesuburan tanah melalui: penyediaan unsur hara tanah, meningkatkan KTK, memperbaiki struktur tanah, dan memperbaiki sifat biologi tanah ${ }^{19)}$.

Hasil penelitian menunjukkan bahwa pengaruh pemberian kapur dan biomas dari tanaman pagar yang dilakukan secara bersama sama (simultan) dalam budidaya lorong yang dilakukan di daerah transmigrasi Kuro Tidur, Bengkulu pada jenis tanah 
podzolik menunjukkan bahwa pengaruh pemberian kapur 2,5 ton/ha dan biomas 5,0 ton/ha dapat meningkatkan hasil jagung dari 22,256 kw/ha menjadi 47,611 kw/ha atau naik $113,92 \%$. Lebih lanjut, pengaruh pemberian kapur 2,5 ton/ha dan biomas 10,0 ton/ha dapat meningkatkan hasil jagung dari 22,256 kw/ha menjadi 50,789 $\mathrm{kw} / \mathrm{ha}$ atau naik $128,20 \%{ }^{15)}$. Meningkatnya produktivitas tanah ini disebabkan oleh lebih tersedianya unsur hara tanah, peningkatan KTK, memperbaiki sifat biologi tanah dan memperbaiki struktur tanah ${ }^{19}$.

Menurut beberapa penelitian, seresah dari tanaman pagar merupakan bahan organik yang mempunyai banyak kelebihan dibandingkan dengan pupuk anorganik, antara lain berperan dalam perbaikan sifat kimia, fisik, dan biologi tanah ${ }^{16)}$. Dari perbaikan sifat kimia tanah, bahan organik mengandung berbagai unsur hara baik makro maupun mikro yang lengkap dan mampu meningkatkan daya ikat tanah terhadap unsur-unsur hara tanaman. Meskipun pupuk organik mengandung kadar unsur hara yang relatif rendah, namun mempunyai peran yang penting yaitu: (a). Menyediakan hara makro dan mikro seperti $\mathrm{Zn}, \mathrm{Cu}$, Mo, Co, Ca, Mg, dan Si, (b). Meningkatkan kapasitas tukar kation (KTK) tanah, dan (c). Dapat bereaksi dengan ion logam untuk membentuk senyawa kompleks, sehingga ion logam yang meracuni tanaman atau menghambat penyediaan hara seperti Al, Fe dan Mn dapat dikurangi ${ }^{5}$.

Sedangkan peran bahan organik dalam perbaikan sifat fisik tanah antara lain adalah: (a). Memperbaiki struktur tanah atau menggem-burkan tanah, (b). Menambah daya serap air, (c). Memperbaiki drainase dan tata udara dalam tanah, dan (d). Memperbaiki kehidupan mikroorganisme tanah yang berguna dalam menyuburkan tanah ${ }^{8)}$. Lebih lanjut, bahan organik mempunyai peran dalam pembentukan agregat tanah karena adanya kandungan komponen organik seperti asam humat dan asam fulvat yang berperan sebagai semen dalam pembentukan komplek lempunglogam-humus ${ }^{20)}$. Pada tanah pasiran, bahan organik dapat berperan merubah struktur tanah dari berbutir tunggal menjadi bentuk gumpal sehingga meningkatkan derajat struktur dan ukuran agregat atau meningkatkan kelas struktur tanah dari halus menjadi sedang atau kasar sehingga lebih mudah untuk diolah ${ }^{18)}$. Keadaan ini lebih lanjut akan mempengaruhi terhadap tingkat porositas, penyimpanan air serta aerasi tanah maupun temperatur tanah ${ }^{5}$.

Adapun peran bahan organik dalam perbaikan sifat biologi tanah adalah melalui peningkatan aktivitas mikroorganisme asli (indogenus) dalam tanah yang menguntungkan, seperti mycorhiza, rhizobium, dan bakteri pelarut fosfat. Menurut penelitian menunjukkan bahwa penggunaan bahan organik yang didekomposisi dengan menggunakan aktivator EM-4 (Effective Microorganism) dalam jumlah yang memadai akan membawa dampak meningkatkan kemampuan tanaman untuk menekan serangan hama dan penyakit tanaman ${ }^{16)}$. Lebih lanjut, penggunaan bahan organik ini akan menstimulasi perkembangan berbagai mikro-organisme yang bermanfaat (terutama bakteri fotosintetik dan bakteri asam laktat, ragi, actinomycetes, dan jamur peragian) yang sangat bermanfaat untuk penyuburan tanah ${ }^{16)}$. Adanya perbaikan produktivitas tanah yang meliputi perbaikan sifat fisik tanah, sifat kimia tanah dan aktivitas biologi tanah yang sangat berperan dalam menunjang pertumbuhan tanaman pada akhirnya akan berdampak meningkatkan produksi tanaman (pangan/semusim) yang ditanam pada lorongnya.

Lebih jauh lagi, penelitian yang dilakukan oleh Wynne Thurne bahwa pemberian biomas dalam budidaya lorong mampu meningkatkan hasil jagung secara nyata karena biomas yang sudah terdekomposisi akan mengikat aluminium (Al) tanah menjadi senyawa khelat yang kompleks sehingga tidak meracuni tanaman ${ }^{22)}$. Dampak dari kasus ini adalah mengurangi kebutuhan 
kapur dalam jumlah banyak, dimana fungsi kapur akan menetralkan tanah yang bisa digantikan dengan biomas yang diperoleh dari hasil pangkasan tanaman pagar. Dengan demikian pertanian budidaya lorong (Alley cropping) ini sangat efektif untuk konservasi lahan, seperti: mengendalikan erosi, memperbaiki sifat fisik dan kimia tanah, aktivitas biologi tanah serta dapat meningkatkan dan mempertahankan produksi tanaman pangan.

Kombinasi penggunaan biomas dari hasil pangkasan daun dan ranting tanaman pagar Flemengia congesta dan kapur dolomit berpotensi secara signifikan dalam penyuburan/peningkatan produktivitas lahan, khususnya dalam budidaya tanaman jagung. Oleh karena itu cara budidaya lorong dengan menggunakan tanaman pagar sebagai penghasil biomas yang relatif cepat, murah, dan mudah ini merupakan teknologi tepat guna yang sangat bermanfaat khususnya untuk konservasi lahan dan air di wilayah hulu DAS Cimanuk.

Lebih lanjut, penerapan sistem budidaya lorong ini diharapkan akan mampu mendukung kinerja secara optimal waduk serbaguna Jati Gede, Kabupaten Sumedang yang saat ini sedang dalam pembangunan. Pembangunan Waduk Jati Gede memiliki peran yang sangat vital karena mampu mengatasi masalah kekeringan dan banjir di sebagian wilayah Pantai Utara (Pantura) Jawa, menjadi sumber air irigasi yang mengairi 90 ribu ha lahan pertanian, menjadi sumber air baku bagi wilayah pantura Jawa, dan Pembangkit Listrik Tenaga Air (PLTA) berkekuatan 110 MW. Menurut rencana waduk Jati Gede ini akan beroperasi mulai tahun $2013{ }^{1}$ ). Diperhitungkan Waduk Serbaguna Jati Gede akan mampu menampung air sebesar satu milyar $\mathrm{m}^{3}$ dengan umur manfaat selama 100 tahun. Fungsi waduk akan berkurang dan umur waduk akan menjadi semakin singkat apabila kondisi DAS Cimanuk dibiarkan tetap kritis sehingga erosi yang terjadi akan mengakibatkan sedimentasi pada waduk. Secara garis besar dampak diterapkannya pengembangan pertanian budidaya lorong di wilayah hulu DAS Cimanuk dideskripsikan pada Gambar 3 sebagai berikut.

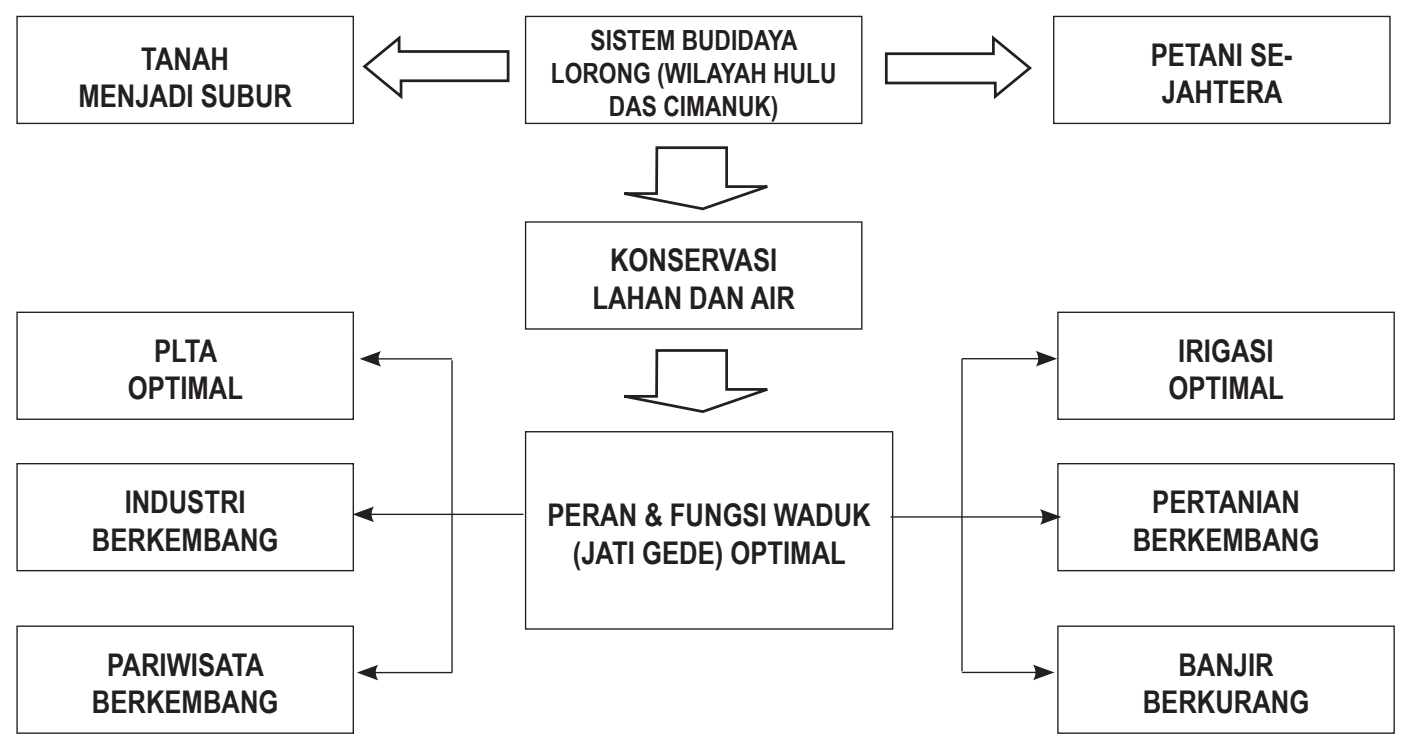

Sumber: ${ }^{14)}$.

Gambar 3. Dampak Pengembangan Budidaya Lorong di DAS Cimanuk 


\section{PENUTUP}

Pada dasarnya ada dua cara penanganan erosi untuk konservasi tanah dan air di wilayah hulu DAS Cimanuk yang kondisinya telah gundul atau kritis, yaitu penanganan secara teknis dan vegetatif, dimana kedua cara tersebut harus dilakukan secara bersama sama atau simultan. Penanganan secara teknis dilakukan dengan cara membangun sistem teras yang berupa teras gulud maupun teras bangku. Sedangkan penanganan secara vegetatif dapat dilakukan dengan cara menanam kembali lahan-lahan kritis dalam suatu sistem usahatani yang berwawasan lingkungan dan menguntungkan seperti budidaya lorong.

Pertanian budidaya lorong ini sangat cocok dilakukan di daerah yang berlereng seperti di wilayah hulu DAS Cimanuk yang memiliki tingkat kelerengan antara 10-30 $\%$, curah hujan yang tinggi mengakibatkan tanah menjadi gundul dan kesuburan tanah menurun karena adanya erosi yang membawa lapisan tanah bagian atas (top soil) yang subur. Tercatat luas lahan kritis di DAS Cimanuk saat ini telah mencapai 131.384 hektar atau sekitar $36,6 \%$ dari luas DAS dan rasio debit di sungai Cimanuk mencapai 251. Tingginya rasio ini menunjukkan tingkat kerusakan DAS yang sudah sangat parah dan sekaligus merupakan potret buruknya pengelolaan DAS. Oleh karena itu diperlukan penanganan yang tepat dan memadai seperti penerapan sistem budidaya lorong agar peran dan fungsi DAS Cimanuk dapat terus dipertahankan sehingga bermanfaat bagi kepentingan berbagai sektor yang terkait secara berkesinambungan. Pemahaman mengenai pertanian budidaya lorong ini pun harus ditingkatkan terutama mengenai dimana, kapan dan bagaimana sistem ini diterapkan di masyarakat sehingga menjadi teknologi yang handal untuk tujuan konservasi lahan pertanian.

\section{DAFTAR PUSTAKA}

1. Anonimous. 2009. Laporan Hasil Perjalanan Daytrip Cimanuk Jawa Barat (Part I). http://tatanggustawan. blogspot.com/2009/11/laporan-hasilperjalanan-daytrip.html

2. - 2009. Tingkat Kerusakan DAS Cimanuk Tinggi. Sumber: Harian Kompas. Jakarta.

3. ----------- 2007. Petunjuk Teknis Teknologi Konservasi Tanah dan Air. Balai Besar Litbang Sumberdaya Lahan Pertanian. Badan Penelitian dan Pengembangan Pertanian. Departemen Pertanian. Jakarta.

4. $\quad$---- 2006. Seluruh DAS di Jabar Rusak Berat, Kerusakan terjadi pada hulu sungai dan penyangga kawasan hutan. Harian Republika. Sumber: http://www. republika.co.id/ koran_detail.asp?id=274054

5. - ------- 2005. Pupuk Organik. Warta Penelitian dan Pengembangan Pertanian. Vol 27 No 6, tahun 2005. Balai Penelitian Tanah. Bogor.

6. -- 1989. Laporan

Pelaksanaan Kegiatan Demonstrasi Usahatani Konservasi Daerah Transmigrasi. Dinas Pertanian Tanaman Pangan Kabupaten Daerah Tingkat II Bengkulu Utara.

7. Anwar S. 2001. Metode Penelitian Kondisi Fungsi Hidrologis DAS Cimanuk-Cisanggarung dan Beberapa DAS di P. Jawa Melalui Analisis Hidrograf dan Analisis Angkutan Sedimen. Makalah Falsafah Sains Program Pasca Sarjana (S3) Institut Pertanian Bogor (IPB). Bogor.

8. Atmojo. SW. 2003. Peranan Bahan Organik Terhadap Kesuburan Tanah dan Upaya Pengelolaannya. Pidato Pengukuhan Guru Besar IImu Kesuburan Tanah Fakultas Pertanian Universitas Sebelas Maret. Surakarta.

9. Hani L. 2009. DAS Cimanuk 
Memprihatinkan. Sumber: Harian Pikiran Rakyat. Bandung.

10. Haryati U. 2002. Keunggulan dan Kelemahan Sistem Alley Cropping Serta Peluang dan Kendala Adopsinya di Lahan Kering DAS Bagian Hulu. Makalah Pengantar Falsafah Sains. Program Pasca Sarjana (S3) Institut Pertanian Bogor (IPB). Bogor.

11. Isbandi, Mansur Dj, K. Subagyono dan E. Eko Ananto. 2005. Peningkatan Produktivitas Lahan Kering Melalui Konservasi dan Integrasi Ternak. Balai Penelitian Ternak, Balai Penelitian Tanah, dan Pusat Penelitian dan Pengembangan Tanaman Pangan. Badan Penelitian dan Pengembangan Pertanian. Departemen Pertanian. Jakarta.

12. Kirmanto D. 2010. Sungai Cimanuk Masuk Program Prioritas GNKPA. Pusat Pengolahan Data (PUSDATA), Kementerian Pekerjaan Umum Republik Indonesia. Jakarta.

13. Mawardi M.l. 2009. Krisis Sumberdaya Air di Pulau Jawa dan Upaya Penangannya : Proyeksi Tahun 2025. Orasi Pengukuhan Profesor Riset Bidang Hidrologi dan Konservasi Tanah. Badan Pengkajian dan Penerapan Teknologi (BPPT). Jakarta.

14. Mulyono D. 2010. Budidaya Pertanian Sistem Agroforestri di Hulu Daerah Aliran Sungai (DAS) Cimanuk Guna Menunjang Operasionalisasi PLTA di Waduk Serbaguna Jati Gede, Sumedang, Jawa Barat. Proposal Diajukan Untuk Memperoleh Pendanaan Corporate Social Responsibility (CSR) PT PLN Wilayah Jawa Barat.

15. Mulyono D. 2010. Peningkatan Produktivitas Lahan Melalui Pemanfaatan Biomas Tanaman Flemengia congesta Untuk Budidaya Tanaman Jagung di Daerah Transmigrasi Kuro Tidur, Bengkulu.
Jurnal Teknologi Lingkungan BPPT (dalam proses penerbitan). Jakarta.

16. Nasir. SP 2007. Pengaruh Penggunaan Pupuk Bokashi Pada Pertumbuhan dan Produksi Padi, Palawija, dan Sayuran. Sumber:http://www.deptan.go.id/ daerah_new/banten/dispertanak_ pandeglang/artikel 13.htm

17. Ratnaningsih M. 2000. Pengelolaan Daerah Aliran Sungai Harus Dilakukan Secara Terpadu Dengan Memperhitungkan Harga Air Sebagai Bentuk Pembayaran Jasa Lingkungan. Ringkasan Desertasi Doktor. Sumber:http://www.pps.ui.ac. $\mathrm{id} /$ new/index. php?option=com_ content\&task=view\&id=6\&ltemid=2

18. Scholes. M.C., Swift, O.W., Heal, P.A. Sanchez, JSI., Ingram and R. Dudal, 1994. Soil Fertility Research in Response to Demand for Sustainability. In The Biological Managemant of Tropical Soil Fertility (Eds Woomer, PI. and Swift, MJ.) John Wiley \& Sons. New York.

19. Soepardi. G. et $\underline{\text { al. }}$ 1988. Budidaya Lorong. Teknologi Bermasukan Terjangkau Petani Sebagai Pilihan Berusahatani Konservatif. Institut Pertanian Bogor (IPB). Bogor.

20. Stevenson. FT 1982. Humus Chemistry. John Wiley and Sons, New York.

21. Sudardja D. 2008. Kritis: Kondisi DAS di Jawa Barat. Sumber: http://www.berpolitik. com/ static/myposting/2008/02/ myposting_10354.html

22. Wigena. I.G.P. dan J.S. Adiningsih. 1987. Pengaruh Pengapuran dan Residunya Serta Penambahan Biomas Terhadap Hasil Kedelai Pada Tanah Typic Haplortox Kuamang Kuning. Prosiding Pertemuan Teknis Penelitian Tanah. Pusat Penelitian Tanah, Badan Litbang Pertanian, Departemen Pertanian. Jakarta. 